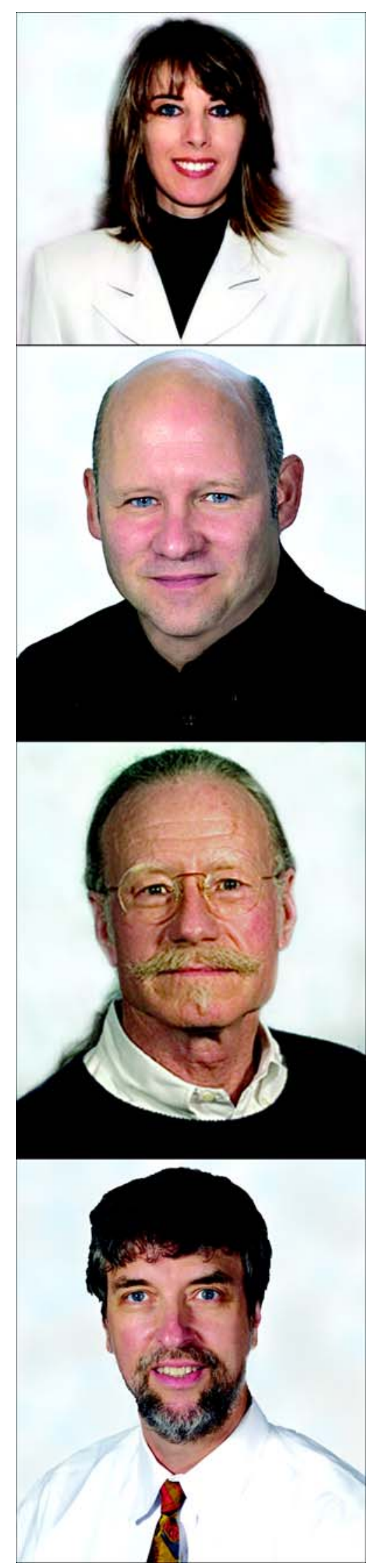

Top to bottom: Lisa Ottomanelli, $\mathbf{P h D}$ Lance L. Goetz, MD Charles McGeough, MS T. Michael Kashner, PhD, JD

\section{Building research capacity through partnerships: Spinal Cord Injury — Vocational Integration Program Implementations and Outcomes inaugural meeting}

\section{INTRODUCTION}

Innovative integration of vocational rehabilitation (VR) services into the healthcare continuum for veterans with spinal cord injury (SCI) was the focus of the inaugural meeting of the "Spinal Cord Injury-Vocational Integration Program (SCI-VIP): Implementations and Outcomes” project, held in Dallas, Texas, November 29 through December 1, 2005. The project is funded through the Department of Veterans Affairs (VA) Office of Research and Development, Rehabilitation Research and Development (RR\&D) Service.

The project launches a new clinical program in response to a serious gap in clinical services for veterans with SCI. Concerned clinicians and experts in the fields of both SCI and VR discovered that although veterans with SCI receive other healthcare and rehabilitation services through the comprehensive continuum of SCI care in the Veterans Health Administration (VHA), they are underserved in the area of VR. In response to this problem, the SCIVIP was developed by Lisa Ottomanelli, PhD, Psychologist at the VA North Texas Healthcare System's Spinal Cord Injury Center and SCI-VIP Principal Investigator; Charles McGeough, MS, National Marketing Director for VA Psychosocial Rehabilitation and SCI-VIP Coinvestigator; and Lance L. Goetz, MD, SCI-VIP Coprincipal Investigator. As the original concepts behind the SCI-VIP evolved, the project also benefited from the guidance of Anthony Campinell, PhD, VA Central Office, Director for Therapeutic and Supported Employment Services, and the advisement of well-informed VR clinicians in the field from VA's Compensated Work Therapy (CWT) Programs.

RR\&D Service considered this new program a timely and fast-developing approach to the lack of effective VR in SCI rehabilitation as we face new challenges in providing services to newly injured, often young, veterans. Recognizing the importance of finding solutions rapidly, RR\&D Service supported the simultaneous development and evaluation of the program through a multisite study. The study documents the implementation of the program and provides a vehicle to efficiently inform clinicians, researchers, and administrators of the best methods for providing these necessary rehabilitation services. Thus, the study embodies a true marriage of research and development by evaluating outcomes of an intervention while it is still in development. 


\section{CONVENTIONAL VOCATIONAL SERVICES}

Traditionally, veterans with SCI who are interested in returning to work are referred outside the VHA SCI centers to VR providers who may not have expertise in SCI. This involves referrals to state VR providers, and services vary widely depending on funding support and caseload volume. Outside referrals often do not achieve desired outcomes because (1) they involve general VR services that are not specifically suited to persons with SCI, (2) their systems are difficult for a person with SCI to access, and (3) they lack supported employment services for patients with SCI after they return to work.

\section{SPINAL CORD INJURY - VOCATIONAL INTEGRATION PROGRAM}

The SCI-VIP is a new method of service delivery that integrates VR services into the SCI continuum of healthcare by including a specially trained VR counselor (VRC). The VRC works within two disciplines, SCI and CWT, to provide highly individualized vocational services in a coordinated fashion within the context of the SCI healthcare team. While using a similar approach to VA's CWT Program's evidencebased supported employment (SE) model, the SCIVIP offers VR services by merging the expertise and resources of two distinct treatments teams, a novel approach to VR within the healthcare system.

The CWT Program has proven over the years to be a successful approach to employment for veterans with severe mental disabilities, homelessness, and substance abuse by employing best practices, including rapid job-seeking, assertive engagement, ongoing assessment, and regular follow-along supports. We hope the SCI-VIP will extend some of these best practices to assist veterans with severe physical disability due to SCI in their vocational pursuits while concurrently attending to their complex physical and medical rehabilitation needs. The goal of the SCI-VIP multisite study is to determine whether participation in the SCI-VIP will improve vocational outcomes for veterans with SCI when compared with current VA practices.

\section{MEETING OBJECTIVES}

The primary goal of the SCI-VIP meeting was to introduce the project and train the clinical and research staff who will administer it. Additional objectives were to (1) establish a viable infrastructure to support the research plan; (2) motivate and raise awareness and enthusiasm for the project among direct and indirect participants; (3) cultivate partnerships with stakeholders, advocates, and public agencies with shared interests; and (4) introduce, stimulate, and merge the collective knowledge and learning from two distinct fields of study (SCI and VR).

\section{ESTABLISHING THE CONTEXT}

Relevant research needs to be understood in relation to its scientific, public, and clinical merit within a broader context. Hence, key meeting participants included leaders in the fields of VR and SCI, researchers, academic department chairs, consumer groups, healthcare administrators, governmental funding agencies, and representatives from the Social Security Administration (SSA) and Veterans Benefits Administration.

To understand and appreciate the significance of the present undertaking, these leaders and representatives from varying perspectives shared their conceptualization of the value of the work at hand. Their participation and contributions to the meeting demonstrated that they embrace the new service model of the SCI-VIP and appreciate the importance of evaluating it with scientific research methods.

Denise Burton, $\mathrm{PhD}$, former Portfolio Manager for Chronic Medical Diseases with RR\&D Service, emphasized the importance of the SCI-VIP's implementation in light of the present military conflicts in Iraq and Afghanistan. Because of the increased number of military personnel who survive combat-related injuries and return home, services need to be available to fulfill their desire to return to productive lives. Robert L. Ruff, MD, PhD, Acting Director of RR\&D Service, echoed this sentiment, citing the decrease in deaths but increase in polytraumatic injuries, especially of the blast type. Dr. Ruff also cited VA's 
strength as an "integrated healthcare" system, which positions it as the "best site for outcomes research" incorporating VR into the total rehabilitation picture. He recognized Dr. Margaret Hammond's contributions in creating a nationwide network for SCI care in VA.

Margaret Hammond, MD, Chief Consultant for VA SCI Strategic Healthcare Group, spoke of the variability of VR services offered in the present system of care, with services currently lacking in many SCI centers. Hammond acknowledged that medical providers tend to focus on short-term medical goals, including mobility, activities of daily living, and adjustment to SCI. However, she noted the "longterm goal of VR tends to fall down on our priority list." She recognized the present meeting and project as an example of "building research capacity," citing the collaborative nature of this research as a strength of the program.

Anthony Campinell, PhD, VA Central Office, Director for Therapeutic and Supported Employment Services, reviewed the inception and visions behind the SCI-VIP project, recognizing the role of Paralyzed Veterans of America (PVA) in bringing the problem of poor employment among SCI veterans to the forefront and garnering support for the project at the national level of VA. Dr. Campinell drew attention to the significant paradigm shift represented in the project; that is, elevating VR from what was "formerly merely an outcome of care" to an "integral part" of the treatment process for SCI. He emphasized the importance of creating an infrastructure to provide care early in the healthcare process. Additionally, he outlined how the project represents an expansion of CWT by using concepts demonstrated as effective with past work with mental health areas and applying them to SCI.

John Bollinger, Deputy Executive Director of PVA, voiced his appreciation for including PVA early in the inception of the project, as well as his belief that the building blocks were in place to give the concept an appropriate trial.

Mr. Bollinger poignantly stated, "We have seen incredible changes over the years in restoration of function, advancement in the possibility of finding a cure, improvements in assistive technology, the
ADA [Americans with Disabilities Act of 1990], civil rights, housing, and transportation. It's ironic that after all these years and all this hard work, here we are today with the same dismal unemployment rate we had among vets with SCI that we had 20 to 30 years ago." He concluded that discrimination alone could not account for this unemployment rate and that "we need to get to the bottom [of] this dismal unemployment rate." He affirmed that PVA is "behind the project 100 percent."

Karen Kowalske, MD, Professor and Chair of the Department of Physical Medicine and Rehabilitation at University of Texas Southwestern Medical School, pledged support for the project, discussing its concordance with the institution's strategic plan for elevating clinical science and research.

In addition to outlining the scope and significance of the project in terms of changing methods of service delivery as discussed previously, Dr. Lisa Ottomanelli, Assistant Professor of Physical Medicine and Rehabilitation at the University of Texas Southwestern Medical School and the study's Principal Investigator, along with Coinvestigator T. Michael Kashner PhD, JD, Professor of Psychiatry at the University of Texas Southwestern Medical School and Director of the Center for Education and Program Analysis with VA, shared the design and methodology behind the project. The SCI-VIP project represents the first multicenter randomized interventional trial of VR for veterans with SCI. In addition to employment outcomes, the project will provide new information regarding quality of life, depression, and healthcare use and costs among veterans with SCI. A comprehensive literature review and methods paper is beyond the scope of this brief editorial and will be disseminated in a later manuscript.

\section{PAST EVIDENCE AND FUTURE ASPIRATIONS}

Keynote speaker Paul Wehman, PhD, Director of the Virginia Commonwealth University Rehabilitation Research and Training Center on Workplace Supports and Job Retention, provided an inspiring overview of the potential benefits of the 
SCI-VIP project to veterans with SCI and the larger community and shared his observations that clinicians often fail to "prescribe" work as an important therapy to help their patients get better. He reviewed the well-accepted literature evidence of the benefits of returning to work and the barriers. Dr. Wehman cited the threats to successful completion of the project, such as recruitment and retention of subjects. Wehman stressed that overcoming such threats will be critical to creating a study that will produce reliable data and be used as a basis for good clinical practices in the future. Past research by Drake and others used the model of SE developed by Wehman and colleagues and applied it to the population of veterans with homelessness and substance-abuse histories. These researchers performed rapid placement of persons coming out of day-treatment programs and multiple studies that proved convincingly that people with severe mental health problems could work competitively, especially if put to work early. Similar rich data are lacking, however, for SCI or other disabling diagnoses.

Dr. Wehman contrasted the older model of waiting until medical or psychosocial issues resolve before placement with a newer model emphasizing rapid placement and concurrent treatment of medical or psychosocial problems. He likened the process to a "SWAT team" approach, led by an enthusiastic, "can do" VRC and a talented treatment team. In this scenario, early and frequent communication with the client, employers, coworkers, and others and the creation of support networks are critical to creating an environment of interdependence. The VRC uses tools such as job carving, onsite work supports, employee accommodation, and employer negotiation to create the right fit for the client.

Dr. Wehman stressed the importance of finding a workplace culture that supports the values of the SE model. A large survey recently demonstrated the support of the American public for employment of persons with disabilities. More than 80 percent of respondents reported that they prefer to give their business to businesses that hire persons with disabilities.

Dr. Wehman summarized the SCI-VIP kickoff as "one of the most important days in the history of mankind for community services for persons with SCI," because the project represents the first major multicenter prospective study in this area.

\section{BRIDGING THE GAP: INTEGRATING SCI AND VOCATIONAL SERVICES}

Robert Rosenheck, MD, Director of the Northeast Program Evaluation Commission and Professor of Psychiatry at Yale University Medical School, moderated a panel discussion that focused on bridging the gap between SCI and VR services. Panel members included Mr. McGeough, Dr. Campinell, Dr. Goetz, Dr. Wehman, Mr. Bollinger, and Mr. Thomas Stripling, Director of Research for PVA.

The importance of communication over the course of the project was a central theme of the panel's recommendations. Mr. McGeough emphasized the need to "maintain synergy" between SCI and CWT personnel, with the VR specialist being an important link. The benefits of email groups, conference calls, and computerized medical records, as well as the project director's role in coordinating communication were discussed. Study promotion to local personnel and veterans at SCI centers and at the national level was emphasized. Mr. Bollinger encouraged the study staff to "toot your own horn . . . don't keep this a secret." And Mr. Stripling advised to "get the message out to the veteran that this is a positive step toward restoration."

Dr. Goetz discussed the strengths and challenges of the study from the perspective of medical rehabilitation in VA. A pilot study performed by SCI-VIP staff suggests that medical problems are the main reason veterans with SCI do not seek employment. Clearly, “we aren't getting these under control,” Dr. Goetz stated. However, strengths of the VA system of SCI care include excellent access to care, the comprehensive annual evaluation, and the computerized patient record system (CPRS). CPRS allows use of templates for care, as well as clinician reminders for medical problems. Dr. Goetz suggested that vocational status should be part of every SCI physician's template and may warrant a clinical reminder. "As rehabilitation physicians, we are charged with 
treating the whole person. Vocational success is an important rehabilitation outcome.” All eligible veterans with SCI, regardless of the severity or chronicity, should be sought for the project. Dr. Rosenheck pointed out that, from a research perspective, those with the most severe injuries have the most to gain and will enhance the power of the study. We have a "moral imperative" and a public mandate to help those persons most severely affected.

The panel offered many benefits that may be realized for VA through the success of SCI-VIP. The potential exists for a "sea change," or paradigm shift, in rehabilitation for veterans with SCI. The project may give veterans a greater voice to increase awareness of legislators in Washington, DC, of the issues surrounding employment and SCI. "Work is the single best way to give someone an identity other than being disabled," Campinell said.

\section{BUILDING PARTNERSHIPS TO SUPPORT RESEARCH}

The possible impact of employment on disability benefits and future finances is considerably important to veterans in decision making about employment after an injury. SCI-VIP researchers seek to provide potential research participants with the most accurate information possible regarding benefits and employment and explore the relationship between disability benefits and employment decision making. To accomplish this objective, we enlisted the assistance of the SSA Benefits Planning Assistance and Outreach (BPAO) program and the PVA Veterans Benefits Department. Both of these entities already routinely provide benefits counseling as part of their mission. Incorporating this process into the study involved sharing the goals and methods of the study with the respective organizations and finding opportunities to enhance shared goals such as educating consumers about work and disability benefits for a common purpose and assisting persons with disabilities in choosing a course of action to maximize independence.

Lessons learned from this process of collaboration were plentiful, as illustrated by the plenary ses- sion that included both SSA and BPAO. As Louis Irvin, Associate Executive Director, for PVA Veterans Benefits Department, pointed out, "CWT is interesting because while a veteran with catastrophic injury is enrolled in the CWT program, their service-connected and nonservice-connected VA benefits are protected. This allows a veteran to learn about work without the threat of losing their benefits. However, the veteran needs to be alerted that after CWT, their future VA benefits will be evaluated against work income." At the session, representatives from SSA shared how work earnings will affect benefits as well as how mechanisms called "subsidy" and "special conditions" can offset income during and after trial work periods.

\section{DEMONSTRATION OF ACTIVE TREATMENT APPROACH}

One of the key elements in the active treatment being studied is a recovery-oriented interview that has been used in evidence-based SE practices in CWT. Rich Toscano, Management Consultant with the University of Georgia, provided live training to the clinical study staff at the meeting on use of this particular approach to vocational assessment. Through live demonstration of this interview technique, the VRCs were able to understand how to assess what is important to the individual with SCI, what he or she hopes to accomplish, and what constitutes an obstacle to gainful career development.

\section{FIDELITY}

Consultants who will be performing fidelity measurement throughout the study outlined its purpose and nature at this inaugural training meeting. Fidelity is the measure of how closely practice adheres to a prescribed model. SCI-VIP will provide vocational services consistent with the eight principles of evidence-based SE and will measure fidelity against that model. Integration of vocational services in the medical continuum of care where the VRC becomes part of the veteran's interdisciplinary 
team is foremost in these principles. Fidelity measures examine key parameters such as caseload size, staff function, ongoing assessment, assertive engagement, rapid search for a competitive job, diversity of jobs, and locus of the job within the community.

\section{CONCLUSIONS}

This SCI-VIP inaugural training meeting did much more than outline a need and a mechanism to implement and test a new method of service delivery through research - it provided a vehicle for an enormously productive interchange between multiple levels of state, federal, clinical, research, and veteran stakeholders and advocates that established a solid infrastructure to launch the project. The interdependent collaboration and forging of working partnerships were predominating and palatable presences throughout the meeting. Although this level of collaboration and interagency cooperation can be challenging to accommodate at an initial research meeting, it ultimately positions a research study to extract a rich harvest of clinically relevant findings over the life of the project. Thus, the project clearly provides a noteworthy example of clinicians and patients working together with researchers on developing and evaluating a new treatment method, with the ultimate goal of translating findings in a timely manner into a meaningful solution for future use.

\section{Lisa Ottomanelli, PhD; $;^{1-2 *}$ Lance L. Goetz,} MD; $;^{1-2}$ Charles McGeough, MS; ${ }^{3}$ T. Michael Kashner, PhD, JD ${ }^{4-5}$

${ }^{1}$ Spinal Cord Injury Center, Department of Veterans Affairs (VA) North Texas Healthcare System, Dallas, TX; ${ }^{2}$ Department of Physical Medicine and Rehabilitation, University of Texas Southwestern Medical School, Dallas, TX; ${ }^{3}$ VA Central Office, Mental Health Strategic Healthcare Group, Dallas, $\mathrm{TX} ;{ }^{4}$ VA Office of Academic Affiliations, Center for Education and Program Analysis, Dallas, TX; ${ }^{5}$ Department of Psychiatry, University of Texas Southwestern Medical School, Dallas, TX

*Email: lisa.ottomanelli@va.gov

DOI: 10.1682/JRRD.2006.06.0072 